VoL. $62(2000)$ [75-85]

\title{
COMMON FIXED POINT THEOREMS FOR TWO MAPPINGS SATISFYING SOME CONDITIONS
}

\author{
Jeong Sheok Ume AND Jong KYu Kim
}

In this paper, using the concept of $w$-distance, we first prove common fixed point theorems in a complete metric space. Then these theorems are used to improve Kannan's fixed point theorem, Ćirićs fixed point theorem, Kada, Suzuki and Takahashi's fixed point theorem and Ume's fixed point theorem.

\section{INTRODUCTION}

In 1996, Kada, Suzuki and Takahashi [2] introduced the concept of $w$-distance on a metric space as follows: Let $X$ be a metric space with metric $d$. Then a function $p: X \times X \rightarrow[0, \infty)$ is called a $w$-distance on $X$ if the following are satisfied:

(1) $p(x, z) \leqslant p(x, y)+p(y, z)$ for any $x, y, z \in X$

(2) for any $x \in X, p(x, \cdot): X \rightarrow[0, \infty)$ is lower semicontinuous,

(3) for any $\varepsilon>0$, there exists $\delta>0$ such that $p(z, x) \leqslant \delta$ and $p(z, y) \leqslant \delta$ imply $d(x, y) \leqslant \varepsilon$.

Recently, Ume [4] proved the following fixed point theorem: Let $X$ be a complete metric space with metric $d$ and let $p$ be a $w$-distance on $X$. Let $T$ be a mapping of $X$ into itself satisfying

$$
p(T x, T y) \leqslant q \cdot \max \{p(x, y), p(x, T x), p(y, T y), p(x, T y), p(y, T x)\}
$$

for all $x, y \in X$ and some $q \in[0,1)$ and

$$
\inf \{p(x, u)+p(x, T x): x \in X\}>0
$$

for every $u \in X$ with $u \neq T u$. Then

(1) $\lim _{n} T^{n} x=y$,

(2) $p\left(T^{n} x, y\right) \leqslant\left[q^{n-1} /(1-q)^{2}\right] \cdot a(x)$ for every $x \in X$,

(3) $T$ has a unique fixed point $y$ in $X$ and $p(y, y)=0$,

where $a(x)=p(x, x)+p(x, T x)+p(T x, x)$.

In this paper, using the concept of $w$-distance, we first prove common fixed point theorems in a complete metric space. Then these theorems are used to improve Kannan's fixed point theorem [3], Ćirić's fixed point theorem [1], Kada, Suzuki and Takahashi's fixed point theorem [2] and Ume's fixed point theorem [4].

Received 28th September, 1999

The authors wish to acknowledge the financial support of the Korea Research Foundation made in the program year of (1998), project no. 1998-015-D00026.

Copyright Clearance Centre, Inc. Serial-fee code: 0004-9727/00 \$A2.00+0.00. 


\section{Preliminaries}

Throughout this paper we denote by $N$ the set of all positive integers and by $R$ the set of all real numbers.

Definition 2.1: Let $(X, d)$ be a metric space, let $p$ be a $w$-distance on $X$ and let $S$ and $T$ be two mappings of $X$ into itself. For $A \subset X$, let $\delta(A)=\sup \{p(x, y)$ : $x, y \in A\}$ and for each $x \in X$, let

$$
\begin{aligned}
O_{S, T}(x, n) & =\left\{x, S x, S^{2} x, \cdots, S^{n} x, T x, T^{2} x, \cdots, T^{n} x\right\}, \quad n=1,2, \cdots, \\
O_{S, T}(x, \infty) & =\left\{S^{i} x: i \in N \cup\{0\}\right\} \cup\left\{T^{j} x: j \in N\right\} .
\end{aligned}
$$

The following lemmas are fundamental.

Lemma 2.2. [2] Let $X$ be a metric space with metric $d$ and let $p$ be a $w$ distance on $X$. Let $\left\{x_{n}\right\}$ and $\left\{y_{n}\right\}$ be sequences in $X$, let $\left\{\alpha_{n}\right\}$ and $\left\{\beta_{n}\right\}$ be sequences in $[0, \infty)$ converging to 0 , and let $x, y, z \in X$. Then the following hold:

(i) If $p\left(x_{n}, y\right) \leqslant \alpha_{n}$ and $p\left(x_{n}, z\right) \leqslant \beta_{n}$ for any $n \in N$, then $y=z$. In particular, if $p(x, y)=0$ and $p(x, z)=0$, then $y=z$;

(ii) if $p\left(x_{n}, y_{n}\right) \leqslant \alpha_{n}$ and $p\left(x_{n}, z\right) \leqslant \beta_{n}$ for any $n \in N$, then $\left\{y_{n}\right\}$ converges to $z$;

(iii) if $p\left(x_{n}, x_{m}\right) \leqslant \alpha_{n}$ for any $n, m \in N$ with $m>n$, then $\left\{x_{n}\right\}$ is a Cauchy sequence;

(iv) if $p\left(y, x_{n}\right) \leqslant \alpha_{n}$ for any $n \in N$, then $\left\{x_{n}\right\}$ is a Cauchy sequence.

Lemma 2.3. Let $(X, d)$ be a metric space and let $p$ be a $w$-distance on $X$. Let $S$ and $T$ be two mappings of $X$ into itself such that

$$
\begin{array}{r}
\text { (2.1) } \max \{p(S x, T y), p(T y, S x)\} \leqslant q \cdot \max \{p(x, y), p(y, x), p(x, S x) \\
p(S x, x), p(y, T y), p(T y, y), p(y, S x), p(S x, y), p(x, T y), p(T y, x)\}, \\
(2.2) \quad p(S x, S y) \leqslant q \cdot \max \{p(x, y), p(y, x), p(x, S x), \\
p(S x, x), p(y, S y), p(S y, y), p(x, S y), p(S y, x), p(y, S x), p(S x, y)\},
\end{array}
$$

and

$$
\begin{aligned}
p(T x, T y) & \leqslant q \cdot \max \{p(x, y), p(y, x), p(x, T x) \\
& p(T x, x), p(y, T y), p(T y, y), p(x, T y), p(T y, x), p(y, T x), p(T x, y)\}
\end{aligned}
$$

for all $x, y \in X$ and some $q \in[0,1)$. Then

(1) For each $x \in X, n \in N$ and $i, j \in N$ with $i, j \leqslant n$,

$$
\max \left\{p\left(S^{i} x, T^{j} x\right), p\left(T^{j} x, S^{i} x\right), p\left(S^{i} x, S^{j} x\right), p\left(T^{i} x, T^{j} x\right)\right\} \leqslant q \cdot \delta\left(O_{S, T}(x, n)\right) .
$$


(2) For each $x \in X$ and $n \in N$, there exist $k_{1}, k_{2}, l_{1}, l_{2} \in N$ with $k_{1}, k_{2}, l_{1}, l_{2}$ $\leqslant n$ such that

$$
\max \left\{p(x, x), p\left(x, S^{k_{1}} x\right), p\left(S^{k_{2}} x, x\right), p\left(x, T^{l_{1}} x\right),\left(T^{l_{2}} x, x\right)\right\}=\delta\left(O_{S, T}(x, n)\right) .
$$

(3) For each $x \in X$,

$$
\delta\left(O_{S, T}(x, \infty)\right) \leqslant \frac{1}{1-q}\{p(x, x)+p(x, S x)+p(S x, x)+p(x, T x)+p(T x, x)\} .
$$

(4) For each $x \in X,\left\{S^{n} x\right\}_{n=1}^{\infty}$ and $\left\{T^{n} x\right\}_{n=1}^{\infty}$ are Cauchy sequences.

Proof: Let $x \in X, n \in N$ and let $i$ and $j$ be natural numbers with $i, j \leqslant n$. Then $S^{i-1} x, S^{i} x, S^{j-1} x, S^{j} x, T^{i-1} x, T^{i} x, T^{j-1} x, T^{j} x \in O_{S, T}(x, n)$, where it is understood that $S^{0} x=x$ and $T^{0} x=x$. From (2.1), (2.2) and (2.3), we have

$$
\begin{gathered}
p\left(S^{i} x, T^{j} x\right) \leqslant \max \left\{p\left(S^{i} x, T^{j} x\right), p\left(T^{j} x, S^{i} x\right)\right\} \\
\leqslant q \cdot \max \left\{p\left(S^{i-1} x, T^{j-1} x\right), p\left(T^{j-1} x, S^{i-1} x\right), p\left(S^{i-1} x, S^{i} x\right),\right. \\
p\left(S^{i} x, S^{i-1} x\right), p\left(T^{j-1} x, T^{j} x\right), p\left(T^{j} x, T^{j-1} x\right), \\
p\left(T^{j-1} x, S^{i} x\right), p\left(S^{i} x, T^{j-1} x\right), p\left(S^{i-1} x, T^{j} x\right), \\
\left.p\left(T^{j} x, S^{i-1} x\right)\right\} \\
\leqslant q \cdot \delta\left(O_{S, T}(x, n)\right) .
\end{gathered}
$$

Similarly, we have $p\left(T^{j} x, S^{i} x\right) \leqslant q \cdot \delta\left(O_{S, T}(x, n)\right), p\left(T^{i} x, T^{j} x\right) \leqslant q \cdot \delta\left(O_{S, T}(x, n)\right)$, and $p\left(S^{i} x, S^{j} x\right) \leqslant q \cdot \delta\left(O_{S, T}(x, n)\right)$, which proves (1) of Lemma 2.3. From (1), it follows that for each $x \in X$ and $n \in N$, there exist $k_{1}, k_{2}, l_{1}, l_{2} \in N$ with $k_{1}, k_{2}, l_{1}, l_{2} \leqslant n$ such that

$$
\delta\left(O_{S, T}(x, n)\right)=\max \left\{p(x, x), p\left(x, S^{k_{1}} x\right), p\left(S^{k_{2}} x, x\right), p\left(x, T^{l_{1}} x\right), p\left(T^{l_{2}} x, x\right)\right\},
$$

which proves (2) of Lemma 2.3. From (1) and (2) of Lemma 2.3, we obtain

$$
\begin{aligned}
& p\left(x, S^{k_{1}} x\right) \leqslant p(x, S x)+p\left(S x, S^{k_{1}} x\right) \leqslant p(x, S x)+q \cdot \delta\left(O_{S, T}(x, n)\right), \\
& p\left(S^{k_{2}} x, x\right) \leqslant p\left(S^{k_{2}} x, S x\right)+p(S x, x) \leqslant q \cdot \delta\left(O_{S, T}(x, n)\right)+p(S x, x), \\
& p\left(x, T^{l_{1}} x\right) \leqslant p(x, T x)+p\left(T x, T^{l_{1}} x\right) \leqslant p(x, T x)+q \cdot \delta\left(O_{S, T}(x, n)\right)
\end{aligned}
$$

and

$$
p\left(T^{l_{2}} x, x\right) \leqslant p\left(T^{l_{2}} x, T x\right)+p(T x, x) \leqslant q \cdot \delta\left(O_{S, T}(x, n)\right)+p(T x, x) .
$$


Therefore,

$$
\delta\left(O_{S, T}(x, n)\right) \leqslant \frac{1}{1-q}\{p(x, x)+p(x, S x)+p(S x, x)+p(x, T x)+p(T x, x)\} .
$$

This implies that

$$
\delta\left(O_{S, T}(x, \infty)\right) \leqslant \frac{1}{1-q}\{p(x, x)+p(x, S x)+p(S x, x)+p(x, T x)+p(T x, x)\} .
$$

Therefore, the proof of (3) is complete.

To prove (4), let $x$ be a given point of $X$ and let $x_{n}=S^{n} x$ and $y_{n}=T^{n} x$ for every $n \in N \cup\{0\}$.

By using (1) and (3) of Lemma 2.3 and from (2.1), (2.2) and (2.3), we obtain

$$
\begin{gathered}
p\left(x_{n}, y_{n}\right) \leqslant q^{2} \cdot \max \left\{p\left(x_{i}, x_{j}\right), p\left(y_{k}, y_{l}\right), p\left(x_{s}, y_{t}\right), p\left(y_{u}, x_{v}\right):\right. \\
n-2 \leqslant i, j, k, l, s, t, u, v \leqslant n\} \\
\leqslant q^{3} \cdot \max \left\{p\left(x_{i}, x_{j}\right), p\left(y_{k}, y_{l}\right), p\left(x_{s}, y_{t}\right), p\left(y_{u}, x_{v}\right):\right. \\
n-3 \leqslant i, j, k, l, s, t, u, v \leqslant n\} \\
\vdots \\
\leqslant q^{n-1} \cdot \max \left\{p\left(x_{i}, x_{j}\right), p\left(y_{k}, y_{l}\right), p\left(x_{s}, y_{t}\right), p\left(y_{u}, x_{v}\right):\right. \\
1 \leqslant i, j, k, l, s, t, u, v \leqslant n\} \\
\leqslant \frac{q^{n-1}}{1-q} \cdot a(x),
\end{gathered}
$$

$$
p\left(x_{n}, x_{n+1}\right) \leqslant \frac{q^{n-1}}{1-q} \cdot a(x)
$$

and

$$
p\left(y_{n}, y_{n+1}\right) \leqslant \frac{q^{n-1}}{1-q} \cdot a(x)
$$

where

$$
a(x)=p(x, x)+p(x, S x)+p(S x, x)+p(x, T x)+p(T x, x) .
$$

By (2.5) and (2.6), we have

$$
\begin{aligned}
p\left(x_{n}, x_{m}\right) & \leqslant p\left(x_{n}, x_{n+1}\right)+\cdots+p\left(x_{m-1}, x_{m}\right) \\
& =\sum_{k=0}^{m-n-1} p\left(x_{n+k}, x_{n+k+1}\right) \\
& \leqslant \sum_{k=0}^{m-n-1} \frac{q^{n+k-1}}{1-q} \cdot a(x) \\
& \leqslant \frac{q^{n-1}}{(1-q)^{2}} \cdot a(x) .
\end{aligned}
$$


Similary, we have

$$
p\left(y_{n}, y_{m}\right) \leqslant \frac{q^{n-1}}{(1-q)^{2}} \cdot a(x) .
$$

From (2.7), (2.8) and Lemma 2.2, $\left\{S^{n} x\right\}$ and $\left\{T^{n} x\right\}$ are Cauchy sequences. Thus the proof of (4) is complete.

LEMMA 2.4. Let $(X, d)$ be a metric space and let $S$ and $T$ be two mappings of $X$ into itself such that

$$
\begin{array}{r}
d(S x, T y) \leqslant q \cdot \max \{d(x, y), d(x, S x), d(y, T y), d(y, S x), d(x, T y)\} \\
d(S x, S y) \leqslant q \cdot \max \{d(x, y), d(x, S x), d(y, S y), d(y, S x), d(x, S y)\}
\end{array}
$$

and

$$
d(T x, T y) \leqslant q \cdot \max \{d(x, y), d(x, T x), d(y, T y), d(y, T x), d(x, T y)\}
$$

for all $x, y \in X$ and some $q \in[0,1)$. Then,

$$
\inf \{d(x, u)+d(x, S x)+d(y, T y)+d(S x, T y): x, y \in X\}>0
$$

for every $u \in X$ with $u \neq S u$ or $u \neq T u$.

Proof: Suppose that there exists $z \in X$ with $z \neq S z$ or $z \neq T z$ such that

$$
\inf \{d(x, z)+d(x, S x)+d(y, T y)+d(S x, T y): x, y \in X\}=0 .
$$

Then there exist sequences $\left\{x_{n}\right\}$ and $\left\{y_{n}\right\}$ in $X$ such that

$$
\lim _{n \rightarrow \infty}\left\{d\left(x_{n}, z\right)+d\left(x_{n}, S x_{n}\right)+d\left(y_{n}, T y_{n}\right)+d\left(S x_{n}, T y_{n}\right)\right\}=0 .
$$

Since $d\left(x_{n}, z\right) \rightarrow 0, d\left(x_{n}, S x_{n}\right) \rightarrow 0, d\left(y_{n}, T y_{n}\right) \rightarrow 0$, and $d\left(S x_{n}, T y_{n}\right) \rightarrow 0$, we have $\left\{S x_{n}\right\},\left\{T y_{n}\right\}$ and $\left\{y_{n}\right\}$ converge to $z$. By (2.9), we obtain

$$
d\left(S x_{n}, T z\right) \leqslant q \cdot \max \left\{d\left(x_{n}, z\right), d\left(x_{n}, S x_{n}\right), d(z, T z), d\left(z, S x_{n}\right), d\left(x_{n}, T z\right)\right\}
$$

and

$$
d\left(S z, T y_{n}\right) \leqslant q \cdot \max \left\{d\left(z, y_{n}\right), d(z, S z), d\left(y_{n}, T y_{n}\right), d\left(y_{n}, S z\right), d\left(z, T y_{n}\right)\right\}
$$

Hence we have

$$
d(z, T z) \leq q d(z, T z)<d(z, T z)
$$

and

$$
d(z, S z) \leq q d(z, S z)<d(z, S z) .
$$

These are contradictions. Therefore, for every $u \in X$ with $u \neq S u$ or $u \neq T u$,

$$
\inf \{d(x, u)+d(x, S x)+d(y, T y)+d(S x, T y): x, y \in X\}>0 .
$$




\section{Main Results}

THEOREM 3.1. Let $X$ be a complete metric space with a metric $d$ and let $p$ be a $w$-distance on $X$. Let $S$ and $T$ be two mappings of $X$ into itself satisfying (2.1), (2.2), (2.3) and

$$
\inf \{p(x, u)+p(x, S x)+p(y, T y)+p(S x, T y): x, y \in X\}>0
$$

for every $u \in X$ with $u \neq S u$ or $u \neq T u$. Then

(1) $\lim _{n \rightarrow \infty} S^{n} x=\lim _{n \rightarrow \infty} T^{n} x=y$.

(2) $p\left(S^{n} x, y\right) \leqslant\left[q^{n-1} /(1-q)^{2}\right] \cdot a(x)$ for every $x \in X$, $p\left(T^{n} x, y\right) \leqslant\left[q^{n-1} /(1-q)^{2}\right] \cdot a(x)$ for every $x \in X$, and $p\left(S^{n} x, T^{n} x\right) \leqslant\left[q^{n-1} /(1-q)\right] \cdot a(x)$ for every $x \in X$.

(3) $S$ and $T$ have a unique common fixed point $y$ in $X$ and $p(y, y)=0$,

where

$$
a(x)=p(x, x)+p(x, S x)+p(S x, x)+p(x, T x)+p(T x, x) .
$$

Proof: Let $x \in X$ and let $x_{n}=S^{n} x$ and $y_{n}=T^{n} x$ for every $n \in N \cup\{0\}$. Then, by (4) of Lemma 2.3, $\left\{x_{n}\right\}$ and $\left\{y_{n}\right\}$ are Cauchy sequences. Since $X$ is complete, there exist $v, z \in X$ such that $\lim _{n \rightarrow \infty} x_{n}=v$ and $\lim _{n \rightarrow \infty} y_{n}=z$. By (2.7), (2.8) and the definition of a $w$-distance $p$, we obtain

$$
p\left(x_{n}, v\right) \leqslant \frac{q^{n-1}}{(1-q)^{2}} \cdot a(x)
$$

and

$$
p\left(y_{n}, z\right) \leqslant \frac{q^{n-1}}{(1-q)^{2}} \cdot a(x) .
$$

From (3.1), (3.2) and Lemma 2.2, we have

$$
v=z
$$

From (2.4), (3.1), (3.2) and (3.3), we obtain (1) and (2). To prove (3), assume that $v \neq S v$ or $v \neq T v$. Then, by (2.4), (2.5), (2.6) and (3.1), we have

$$
\begin{aligned}
0 & <\inf \{p(x, v)+p(x, S x)+p(y, T y)+p(S x, T y): x, y \in X\} \\
& \leqslant \inf \left\{p\left(x_{n}, v\right)+p\left(x_{n}, x_{n+1}\right)+p\left(y_{n}, y_{n+1}\right)+p\left(x_{n+1}, y_{n+1}\right): n \in N\right\} \\
& \leqslant \frac{(4-q) \cdot a(x)}{(1-q)^{2}} \inf \left\{q^{n-1}: n \in N\right\} \\
& =0 .
\end{aligned}
$$


This is contradiction. Therefore we have $v=S v=T v$.

To prove uniqueness, let $u=S u=T u$ and $v=S v=T v$. Then, by (2.3), we have $p(v, v)=p(T v, T v) \leqslant q p(v, v)$,

$$
p(u, v)=p(T u, T v) \leqslant q \cdot \max \{p(u, v), p(v, u)\}
$$

and

$$
p(v, u)=p(T v, T u) \leqslant q \cdot \max \{p(u, v), p(v, u)\} .
$$

Thus we obtain $p(v, v)=p(u, v)=p(v, u)=0$. By Lemma 2.2, we have $u=v$.

In Theorem 3.1, letting $S=T$, we have the following corollaries.

Corollary 3.2. Let $(X, d)$ be a complete metric space and let $p$ be a $w$ distance on $X$. Let $T$ be a mapping of $X$ into itself satisfying (2.3) and

$$
\inf \{p(x, u)+p(x, T x)+p(y, T y)+p(T x, T y): x, y \in X\}>0
$$

for every $u \in X$ with $u \neq T u$. Then

(1) $\lim _{n \rightarrow \infty} T^{n} x=y$,

(2) $p\left(T^{n} x, y\right) \leqslant\left[q^{n-1} /(1-q)^{2}\right] \cdot a(x)$ for every $x \in X$,

(3) $T$ has a unique fixed point $y$ in $X$ and $p(y, y)=0$,

where

$$
a(x)=p(x, x)+2[p(x, T x)+p(T x, x)] .
$$

Corollary 3.4. [4] Let $X$ be a complete metric space with metric $d$ and let $p$ be a $w$-distance on $X$. Let $T$ be a mapping of $X$ into itself satisfying

$$
p(T x, T y) \leqslant q \cdot \max \{p(x, y), p(x, T x), p(y, T y), p(x, T y), p(y, T x)\}
$$

for all $x, y \in X$ and some $q \in[0,1)$. and

$$
\inf \{p(x, u)+p(x, T x): x \in X\}>0
$$

for every $u \in X$ with $u \neq T u$. Then

(1) $\lim _{n} T^{n} x=y$, and

(2) $T$ has a unique fixed point $y$ in $X$ and $p(y, y)=0$.

Corollary 3.4. Let $X$ be a complete metric space with metric $d$ and let $p$ be a $w$-distance on $X$. Let $T$ be a mapping of $X$ into itself satisfying

$$
p(T x, T y) \leqslant \alpha \cdot\{p(x, T x)+p(y, T y)\}
$$


for all $x, y \in X$ and some $\alpha \in[0,1 / 2)$. For every $u \in X$ with $u \neq T u$, suppose

$$
\inf \{p(x, u)+p(x, T x): x \in X\}>0 \text {. }
$$

Then $T$ has a unique fixed point. Moreover, if $v=T v$, then $p(v, v)=0$.

Since a metric $d$ is a $w$-distance, in Theorem 3.1, letting $S=T$ and from Lemma 2.4, we have the following corollaries.

Corollary 3.5. [1] Let $X$ be a complete metric space with metric $d$ and let $T$ be a mapping from $X$ into itself. Suppose $T$ is a quasi-contraction, that is, there exists $q \in[0,1)$ such that

$$
d(T x, T y) \leqslant q \cdot \max \{d(x, y), d(x, T x), d(y, T y), d(x, T y), d(y, T x)\}
$$

for every $x, y \in X$. Then $T$ has a unique fixed point.

Corollar 3.6. [3] Let $X$ be a complete metric space with metric $d$, and let $T$ be a mapping from $X$ into itself. Suppose $T$ is Kannan mapping, that is, there exists $\alpha \in[0,1 / 2)$ such that

$$
d(T x, T y) \leqslant \alpha\{d(x, T x)+d(y, T y)\}
$$

for all $x, y \in X$. Then $T$ has a unique fixed point.

TheOREM 3.7. Let $(X, d)$ be a complete metric space and let $p$ be a $w$-distance on $X$. Let $S$ and $T$ be two mappings of $X$ into itself and let $\varphi: X \rightarrow[0, \infty)$ be a mapping such that

$$
\max \left\{p\left(S x, S^{2} x\right), p\left(T x, T^{2} x\right)\right\} \leqslant q \cdot \varphi(x)
$$

for every $x \in X$ and some $q \in[0,1)$,

$$
\sup \left\{\frac{\varphi(x)}{\min [p(x, S x), p(x, T x)]}: x \in X\right\}<\frac{1}{q}
$$

and

$$
\inf \{p(x, u)+p(x, S x)+p(y, T y): x, y \in X\}>0
$$

for every $u \in X$ with $u \neq S u$ or $u \neq T u$. Then $S$ and $T$ have a common fixed point in $X$.

PROOF: Let

$$
\beta=\sup \left\{\frac{\varphi(x)}{\min [p(x, S x), p(x, T x)]}: x \in X\right\}
$$


and $k=\beta q$. By (i) and (ii), we obtain

$$
p\left(S x, S^{2} x\right) \leqslant k p(x, S x)
$$

and

$$
p\left(T x, T^{2} x\right) \leqslant k p(x, T x)
$$

for all $x \in X$ and some $k \in[0,1)$. Let $x, y \in X$ and define $x_{n}=S^{n} x$ and $y_{n}=T^{n} y$ for all $n \in N$. Then, from (3.4) and (3.5) we have

$$
p\left(x_{n}, x_{n+1}\right) \leqslant k p\left(x_{n-1}, x_{n}\right) \leqslant \cdots \leqslant k^{n-1} p\left(x_{1}, x_{2}\right)
$$

and

$$
p\left(y_{n}, y_{n+1}\right) \leqslant k p\left(y_{n-1}, y_{n}\right) \leqslant \cdots \leqslant k^{n-1} p\left(y_{1}, y_{2}\right)
$$

for all $n \in N$. Let $n$ and $m$ be any natural numbers such that $n<m$. Then, from (3.6), (3.7) we get

$$
\begin{aligned}
p\left(x_{n}, x_{m}\right) & \leqslant p\left(x_{n}, x_{n+1}\right)+\cdots+p\left(x_{m-1}, x_{m}\right) \\
& =\sum_{i=0}^{m-n-1} p\left(x_{n+i}, x_{n+i+1}\right) \\
& \leqslant \sum_{i=0}^{m-n-1} k^{n+i-1} p\left(x_{1}, x_{2}\right) \\
& \leqslant \frac{k^{n-1}}{(1-k)} p\left(x_{1}, x_{2}\right)
\end{aligned}
$$

and similarly

$$
p\left(y_{n}, y_{m}\right) \leqslant \frac{k^{n-1}}{1-k} p\left(y_{1}, y_{2}\right)
$$

By Lemma 2.2, $\left\{x_{n}\right\}$ is a Cauchy sequence. Since $X$ is complete, $\left\{x_{n}\right\}$ converges to some point $u \in X$. Then since $\left\{x_{n}\right\}$ converges to $u$ and $p\left(x_{n}, \cdot\right)$ is lower semicontinuous, from (3.8) we have

$$
p\left(x_{n}, u\right) \leqslant \lim _{m \rightarrow \infty} \inf p\left(x_{n}, x_{m}\right) \leqslant \frac{k^{n-1}}{(1-k)} p\left(x_{1}, x_{2}\right) .
$$


Assume that $u \neq S u$ or $u \neq T u$. Then, by (iii) of Theorem 3.7, (3.8), (3.9) and (3.10), we have

$$
\begin{aligned}
0 & <\inf \{p(x, u)+p(x, S x)+p(y, T y): x, y \in X\} \\
& \leqslant \inf \left\{p\left(x_{n}, u\right)+p\left(x_{n}, x_{n+1}\right)+p\left(y_{n}, y_{n+1}\right): n \in N\right\} \\
& \leqslant \inf \left\{\frac{k^{n-1}}{(1-k)} p\left(x_{1}, x_{2}\right)+k^{n-1} p\left(x_{1}, x_{2}\right)+k^{n-1} p\left(y_{1}, y_{2}\right): n \in N\right\} \\
& =\left\{\frac{2-k}{(1-k)} p\left(x_{1}, x_{2}\right)+p\left(y_{1}, y_{2}\right)\right\} \inf \left\{k^{n-1}: n \in N\right\} \\
& =0 .
\end{aligned}
$$

This is a contradiction. Therefore we have $u=S u=T u$.

From Theorem 3.7, we have the following corollaries

Corollary 3.8. Let $(X, d)$ be a complete metric space and let $p$ be a $w$ distance on $X$. Let $S$ and $T$ be two mappings of $X$ into itself satisfying (iii) of Theorem 3.7,

$$
\begin{aligned}
\max & \left\{p\left(S x, S^{2} x\right), p\left(T x, T^{2} x\right)\right\} \\
& \leqslant q \cdot \max \left\{p(x, S x), p\left(x, S^{2} x\right), p(x, T x), p\left(x, T^{2} x\right)\right\}
\end{aligned}
$$

for all $x \in X$ and some $q \in[0,1)$,

$$
\sup \left\{\frac{\max \left[p(x, S x), p\left(x, S^{2} x\right), p(x, T x), p\left(x, T^{2} x\right)\right]}{\min [p(x, S x), p(x, T x)]}: x \in X\right\}<\frac{1}{q}
$$

Then $S$ and $T$ have a fixed point in $X$.

Proof: Put

$$
\varphi(x)=\max \left[p(x, S x), p\left(x, S^{2} x\right), p(x, T x), p\left(x, T^{2} x\right)\right]
$$

for all $x \in X$. The result follows by Theorem 3.7.

Corollary 3.9. [4] Let $X$ be a metric space with metric $d$ and let $p$ be a $w$-distance on $X$. Let $T$ be a mapping of $X$ into itself satisfying

$$
p\left(T x, T^{2} x\right) \leqslant q \cdot \max \left\{p(x, T x), p\left(x, T^{2} x\right)\right\}
$$

for all $x \in X$ and some $q \in[0,1)$,

$$
\sup _{x \in X}\left\{\frac{p\left(x, T^{2} x\right)}{p(x, T x)}\right\}<\frac{1}{q}
$$


and

$$
\inf \{p(x, u)+p(x, T x): x \in X\}>0
$$

for every $u \in X$ with $u \neq T u$. Then $T$ has a unique fixed point. Moreover, if $v=T v$, then $p(v, v)=0$.

Corollary 3.10. [2] Let $X$ be a complete metric space, let $p$ be a $w$ distance on $X$ and let $T$ be a mapping from $X$ into itself. Suppose that there exists $r \in[0,1)$ such that

$$
p\left(T x, T^{2} x\right) \leqslant r \cdot p(x, T x)
$$

for every $x \in X$ and that

$$
\inf \{p(x, y)+p(x, T x): x \in X\}>0
$$

for every $y \in X$ with $y \neq T y$. Then $T$ has a unique fixed point. Moreover, if $v=T v$, then $p(v, v)=0$.

\section{REFERENCES}

1 L.J. Ćirić, 'A generalization of Banach's contraction principle', Proc. Amer. Math. Soc. 45 (1974), 267-273.

2 O. Kada, T. Suzuki and W. Takahashi, 'Nonconvex minimization theorems and fixed point theorems in complete metric spaces', Math. Japon. 44 (1996), 381-391.

3 R. Kannan, 'Some results on fixed points-II', Amer. Math. Monthly 76 (1969), 405-408.

4 J.S. Ume, 'Fixed point theorems related to Ćirić's contraction principle', J. Math. Anal. Appl. 225 (1998), 630-640.

Department of Applied Mathematics

Changwon National University

Changwon 641-773

Korea

e-mail: jsume@sarim.changwon.ac.kr
Department of Mathematics

Kyungnam University

Masan 631-701

Korea

e-mail: jongkyuk@hanma.kyungnam.ac.kr 